\title{
Expansionary contractions and fiscal free lunches: too good to be true?*
}

\author{
Richard McManus \\ Canterbury Christ Church University \\ Dawid Trzeciakiewicz \\ University of Bradford
}

F. Gulcin Ozkan ${ }^{\dagger}$

University of York

\begin{abstract}
This paper builds a framework to jointly examine the possibility of both 'expansionary fiscal contractions' (austerity increasing output) and 'fiscal free lunches' (expansions reducing government debt), arguments supported by the austerity and stimulus camps, respectively, in recent debates. We propose a new metric quantifying the budgetary implications of fiscal action, a key aspect of fiscal policy particularly at the monetary zero lower bound. We find that austerity needs to be highly persistent and credible to be expansionary, and stimulus temporary, responsive and well-targeted in order to lower debt. We conclude that neither are likely, especially during periods of economic distress.
\end{abstract}

Key words: fiscal policy; expansionary contractions; fiscal free lunch; austerity versus stimulus; and zero lower bound.

JEL Classification: E65; H2; H3.

\footnotetext{
*Comments from the participants at Money, Macro and Finance Annual Conference at Durham University, 17-19 September 2014; the Royal Economic Society Annual Conference at the University of Manchester, 30 March-1 April, 2015; the Macroeconomics Analysis and Application Research Group at the Newcastle University; and at York Fiscal Policy Symposium 18-19 July 2016 are gratefully acknowledged.

${ }^{\dagger}$ Corresponding author. Department of Economics and Related Studies (DERS), University of York, Heslington, York, YO10 5DD, UK; Tel: 01904-434673; E-mail:gulcin.ozkan@york.ac.uk.
} 


\section{Introduction}

The 2008 global financial crisis and subsequent economic downturn led to a deterioration in fiscal balances, resulting in widespread fiscal austerity in a large number of countries. Within this climate, some suggested that fiscal contractions can be expansionary, especially those conducted through spending cuts as agents anticipate efficiency gains and lower future taxes as a result of a smaller public sector (Alesina \& Ardagna 1998). Others, however, indicated that fiscal multipliers are potentially much larger in recessions compared to normal times (see for example Auerbach \& Gorodnichenko 2012) and hence austerity would be even more contractionary in post-crisis periods. This is argued to be particularly the case in the current climate with monetary policy being constrained at its nominal zero lower bound ('ZLB': see for example Eggertsson 2010, Woodford 2011). Furthermore, it is argued, under the ZLB fiscal effectiveness is greatly amplified such that interventions become 'fiscal free lunches' (Erceg \& Lindé 2014); expansionary policy stimulates output and resulting tax revenues to such an extent that there is a fall in government debt.

The innovation of this paper is to develop a formal framework which encompasses the possibility of both 'expansionary contractions' and 'fiscal free lunches'. The former is defined as fiscal contractions leading to an increase in output and the latter as expansions which reduce debt. We test for expansionary contractions by using traditional output multipliers, while we introduce a 'bond multiplier' metric which measures the response of government debt to fiscal interventions to investigate fiscal free lunches. A fiscal free lunch is observed when either spending increases or tax cuts lead to an improvement in government debt. We find that austerity needs to be permanent and credible in order to yield expansionary effects. Agents observe a potential increase in their lifetime earnings if they predict lower future taxes, but they only act on this if they perceive the spending cuts to be credibly long lasting; without this expectation and credibility, expansionary contractions are not possible. In the case of fiscal expansions, we show that fiscal action improves budgetary outcomes when it is temporary, well-targeted and supported by accommodative monetary policy (or 
the ZLB). We conclude that, given the political costs associated with prolonged austerity as well as those of reversing stimulus, neither extreme outcome is likely, and therefore, policymakers are unlikely to benefit from either expansionary contractions or fiscal free lunches.

This paper builds on the literature which finds that fiscal policy, especially with respect to government spending, becomes more effective under a period of the ZLB Eggertsson 2010, Woodford 2011, Christiano et al. 2011). Under such conditions, interest rates are not raised by the central bank who would otherwise respond to increased inflation and output when government spending increases; furthermore, higher inflation with a fixed nominal interest rate leads to a fall in the real interest rate, subsequently fuelling further increases in consumption. Indeed, fiscal policy can become so effective that spending increases lead to substantial rises in the tax base, reducing government debt (Erceg \& Lindé 2014).

We extend the work of Erceg \& Lindé (2014) in two important dimensions. First, we extend the results to many fiscal instruments; our model includes government spending on consumption goods, investment goods, transfers and public employment and distortionary taxes on consumption, labour income, capital income and employers' social security contributions. Whereas fiscal free lunches can occur for increases in spending and cuts in consumption taxes, cuts in production taxes have the opposite effect; a fall in labour, capital or employment taxes leads to lower inflation, subsequently leading to higher real interest rates in the presence of the ZLB, results also identified in Eggertsson (2010). Second, we develop a bond multiplier metric to measure the consequences of fiscal action on government borrowing. We argue that this is particularly important at the ZLB where the budgetary consequences of fiscal actions are different from those in normal times.

Our results also provide a basis for the main findings in the empirical literature on the output effects of fiscal consolidations. This literature identifies two factors as key determinants of the possibility of expansionary contractions: first, the political environment in which the fiscal consolidation is performed; and second, specific fiscal instruments used in the fiscal adjustment. With respect to the former, it has been shown that those fiscal consolidations 
which are against type (parties on the political left cutting spending and those on the right raising taxes) are associated with buying credibility and are more likely to succeed (see for example von Hagen \& Strauch 2001). With respect to the latter, it is found that fiscal consolidations which focus more on spending cuts, especially politically sensitive spending cuts, are more likely to be successful (see for example von Hagen et al. 2002). Indeed, our analysis based on a dynamic stochastic general equilibrium (DSGE) model with a rich set of fiscal instruments reveals that expansionary fiscal contractions are possible, but require a commitment of the fiscal authority that is credibly perceived by private agents as well as a judicious choice of fiscal instruments. We, therefore, argue that these fiscal outcomes are unlikely, and potentially this is why the literature finds only rare occurrences of these events.

The paper proceeds in the following way. The next section builds a DSGE model with a full set of fiscal instruments. Section 3 identifies the circumstances through which expansionary fiscal contractions and fiscal free lunches occur: first by developing a new bond multiplier metric; then conducting a range of fiscal experiments; and finally assessing specific fiscal outcomes, including a series of sensitivity checks on the robustness of the results. Section 4 concludes.

\section{$2 \quad$ Model}

We utilize a DSGE model featuring rigidities in prices and wages, habit formation, adjustment costs in investment and distortionary taxation on employment, labour and capital income, and consumption. In the following subsections, we discuss the operation of each sector in the economy.

\subsection{Households}

There is a continuum $[0,1]$ of infinitely lived households: a proportion of which $(1-\lambda)$ are 'Ricardian' agents who have full access to capital and bond markets; and $(\lambda)$ are 'non- 
Ricardian' agents who each period consume their income 'hand-to-mouth'. Both households supply labour ( $L_{t}^{R}$ and $L_{t}^{N R}$ for Ricardian and non-Ricardian agents, respectively) and consume the final consumption good $\left(C_{t}^{R}\right.$ and $\left.C_{t}^{N R}\right)$. Each Ricardian household, $i$, seeks to maximize:

$$
E_{0} \sum_{t=0}^{\infty} \beta^{t}\left(\ln \left(C_{t}^{R}(i)-h C_{t-1}^{R}(i)\right)-\frac{1}{1+\sigma_{l}}\left(L_{t}^{R}(i)_{t}\right)^{1+\sigma_{l}}\right)
$$

where $E_{0}$ denotes the expectation operator, $\beta \in(0,1)$ the discount factor, $h$ a habit persistence parameter, and $\sigma_{l}$ the inverse of the Frisch labour supply elasticity. The household's total expenditure on consumption, investment in physical capital $\left(I_{t}^{R}\right)$, and accumulation of a portfolio of riskless one-period contingent claims from the government, $B_{t}^{R}$, must be no greater than the household's total disposable income:

$$
\begin{aligned}
\left(1+\tau_{t}^{c}\right) C_{t}^{R}(i)+I_{t}^{R}(i)+B_{t}^{R}(i) \leq & \left(1-\tau_{t}^{l}\right) w_{t}(i) L_{t}^{R}(i)+\Pi_{t}^{R}(i) \\
& +\left(1-\tau_{t}^{k}\right) r_{t} K_{t-1}^{R}(i)+\frac{R_{t-1} B_{t-1}^{R}(i)}{\pi_{t}}+T R_{t}^{R}(i)
\end{aligned}
$$

where $\tau_{t}^{c}, \tau_{t}^{l}$ and $\tau_{t}^{k}$ represent distortionary taxes on consumption, labour income and capital; $w_{t}$ is the real wage; $\Pi_{t}^{R}$ represents dividends from firms, $r_{t}$ the real return on capital services, $K_{t-1}^{R}$ the stock of physical capital; $R_{t-1}$ the gross nominal interest rate on one-period bonds, $\pi_{t}$ the gross inflation rate; and $T R_{t}^{R}$ represents a lump-sum transfer. Physical capital accumulates in accordance with:

$$
K_{t}^{R}=\left(1-\delta_{k}\right) K_{t-1}^{R}+\left[1-\frac{\phi}{2}\left(\frac{I_{t}^{R}}{I_{t-1}^{R}}-1\right)^{2}\right] I_{t}^{R}
$$

where the expression in the square brackets denotes the cost of investment adjustment function $(\phi>0) !$

\footnotetext{
${ }^{1}$ Following Christiano et al. (2005), among others, we assume complete markets for state contingent claims in consumption and assets, thus asset holdings and consumption are equal across all the Ricardian
} 
Non-Ricardian agents are assumed not to have access to credit and bond markets, or equity, and therefore consume their period-by-period income governed by their wage and lump-sum transfers:

$$
\left(1+\tau_{t}^{c}\right) C_{t}^{N R}(i)=\left(1-\tau_{t}^{l}\right) w_{t}(i) L_{t}^{N R}(i)+T R_{t}^{N R}(i)
$$

By definition each household within the economy receives the same amount of transfers from the government, therefore $T R=T R^{N R}=T R^{R}$.

\subsection{Labour market}

A competitive labour union transforms Ricardian households' differentiated labour into composite labour $N$ which is, in turn, supplied to private intermediate firms and to the public sector, such that $N_{t}=N_{t}^{G}+N_{t}^{P}$ where $N_{t}^{G}$ and $N_{t}^{P}$ denotes labour used in the public and private sector respectively. Thus we assume that public and private sectors use the same type of labour and this labour is perfectly mobile between the two sectors $2^{2}$ The technology used in the transformation is defined by $N_{t}=\left[\int_{0}^{1}\left(L_{t}(i)\right)^{\left(\nu_{w}-1\right) / \nu_{w}} d i\right]^{\nu_{w} /\left(\nu_{w}-1\right)}$ where $\nu_{w}$ is the elasticity of substitution among the differentiated labour inputs and $N_{t}$ the aggregate labour index. The competitive union takes every household's wage, $W_{t}(i)$, as given and maximises profit $\Pi_{t}^{U}=W_{t} N_{t}-\int_{0}^{1} W_{t}(i) L_{t}(i) d i$ where $L_{t}(i)$ denotes the amount of labour supplied by household $i$ to the union, and $W_{t}$ is the aggregate wage index. The associated demand function for household's $(i)$ labour is given by: $L_{t}(i)=\left(W_{t}(i) / W_{t}\right)^{-\nu_{w}} N_{t}$. The corresponding aggregate wage index is represented by: $W_{t}=\left[\int_{0}^{1}\left(W_{t}(i)\right)^{1-\nu_{w}} d i\right]^{1 /\left(1-\nu_{w}\right)}$.

Nominal wages are set in a Calvo (1983) wage mechanism. Every period, each Ricardian household faces a probability $\left(1-\theta_{w}\right)$ of being able to adjust their nominal wage. The household then sets nominal wages to maximize utility subject to labour demand; the probability $\theta_{w}$ is fixed, exogenous and independent of when the household was last able to households. Hence, household specific notation is not required in equation (3).

${ }^{2}$ The implication of this assumption is that the wage rate will be identical in the private and the public sector. 
change wages. Those who cannot reoptimize set wages in accordance with the indexation rule $W_{t}(i)=\pi_{t-1}^{\gamma_{w}} W_{t-1}(i)$, where $\gamma_{w} \in\langle 0,1\rangle$ determines the degree of wage indexation.

Each non-Ricardian household sets its wage equal to the average wage of Ricardian households. Given that all households face the same labour demand and supply (thus $L=$ $L^{N R}=L^{R}$ ) the total labour income of each non-Ricardian household is equal to the average labour income of each Ricardian household; this allows for tractable aggregation of nonRicardian labour and is a common assumption applied (see for example Coenen et al. 2013).

\subsection{Production}

The final good, $Y_{t}$, is produced by retailers in a perfectly competitive environment by aggregating the intermediate goods $\left(Y_{j, t}\right)$ with a constant elasticity of substitution technology, $Y_{t}=\left[\int_{0}^{1}\left(Y_{j, t}\right)^{\left(\nu_{p}-1\right) / \nu_{p}} d j\right]^{\nu_{p} /\left(\nu_{p}-1\right)}$, where $\nu_{p}$ denotes the elasticity of substitution among the intermediate goods. Monopolistic firms, indexed by $j \in(0,1)$, use the following production function:

$$
Y_{j, t}=\left(K_{j, t-1}\right)^{\alpha}\left(N_{j, t}^{P}\right)^{1-\alpha}\left(K_{t-1}^{G}\right)^{\alpha_{g}}-\Phi
$$

where $K_{t}^{G}$ denotes public capital and $\Phi$ a fixed cost of production. Intermediate goods producers solve a two-stage problem. First, they minimise real costs, $\left(1+\tau_{t}^{e r}\right) w_{t} N_{j, t}^{P}+r_{t} K_{j, t-1}$, where $\tau_{t}^{e r}$ denotes employers' social security contributions, subject to the production function (5). Second, they choose prices that maximise expected discounted real profits subject to the demand from retailers, $Y_{j, t}=\left(P_{j, t} / P_{t}\right)^{-\nu_{p}} Y_{t}$, where $P_{j, t}$ denotes the price of an intermediate good, $j$, and $P_{t}$ denotes a price index given by: $P_{t}=\left[\int_{0}^{1}\left(P_{j, t}\right)^{1-\nu_{p}} d j\right]^{1 /\left(1-\nu_{p}\right)}$. Each retailer is subject to the same Calvo pricing structure and indexation as in the labour market which is governed by parameters $\theta_{p}$ and $\gamma_{p}$. 


\subsection{Monetary policy}

The monetary authority sets nominal interest rates, $R_{t}$, by following a Taylor rule which responds to deviations in both output and inflation:

$$
R_{t}=\max \left\{1, R\left(\frac{R_{t-1}}{R}\right)^{\rho}\left[\left(\frac{\pi_{t}}{\pi}\right)^{\rho_{\pi}}\left(\frac{G D P_{t}}{G D P}\right)^{\rho_{y}}\right]^{1-\rho}\right\}
$$

where $\rho$ is an interest rate smoothing parameter, and $\rho_{\pi}$ and $\rho_{y}$, respectively, denote the response of interest rates to inflation and GDP deviations from their steady-state values (represented by variables with no time subscript). The nominal interest rate has a lower bound of zero which means that when the Taylor rule computes a negative interest rate it is set to zero. The possibility and length of this ZLB is a key parameter in our analysis.

\subsection{Fiscal policy}

The fiscal authority has eight instruments, four in spending (public purchases of goods and services, investment, employment and transfers: $G^{C}, I^{G}, N^{G}$ and $T R_{t}$, respectively) and four in taxes (on consumption, labour income, capital income and employers' social security contributions: $\tau_{t}^{c}, \tau_{t}^{l}, \tau_{t}^{k}$ and $\tau_{t}^{e r}$, respectively) ${ }^{3}$ The government budget constraint requires that spending be no greater than tax revenues received plus any cash flows from bond market transactions:

$$
G_{t}^{C}+I_{t}^{G}+\left(1+\tau_{t}^{e r}\right) w_{t} N_{t}^{G}+T R_{t}=B_{t}-\frac{R_{t-1} B_{t-1}}{\pi_{t}}+\tau_{t}^{c} C_{t}+\tau_{t}^{l} w_{t} L_{t}+\tau_{t}^{k} r_{t} K_{t-1}+\tau_{t}^{e r} w_{t} N_{t}
$$

Public capital accumulates according to:

\footnotetext{
${ }^{3}$ Note that public employment does not enter the production function $(5)$ as we assume this to be unproductive. The total wage cost of public employment does, however, enter the calculation of total output, as it is added to the total production of the final good. Note also that, as expressed in (7), wages earned through government employment is subject to income tax. Government consumption of privately produced output is also taken to be unproductive in that it does not enter the utility function (1).
} 


$$
K_{t}^{G}=\left(1-\delta_{g}\right) K_{t-1}^{G}+I_{t}^{G}
$$

which is equivalent to the accumulation of private capital (3), but without cost to adjustment, as is common in the literature, and where $\delta_{g}$ represents depreciation specific to public capital.

Our fiscal experiments combine two elements: first a temporary shock is applied which lasts for a predetermined length and is equally distributed over this horizon; second, after this predetermined length, the shock diminishes governed by an autoregressive persistence parameter:

$$
x_{t}=x\left(\frac{B_{t-1}}{B}\right)^{-\varphi_{x}}+\varepsilon_{x, t} ; \quad \varepsilon_{x, t}=\left\{\begin{array}{ll}
\eta_{x} & \text { if } t=1, \ldots, z \\
\rho_{x} \varepsilon_{x, t-1} & \text { if } t>z
\end{array} \quad \rho_{x} \in\langle 0,1\rangle\right.
$$

where $x=\left\{G^{C}, I^{G}, N^{G}, T R, \tau^{c}, \tau^{l}, \tau^{k}, \tau^{e r}\right\}$, and where $\varphi_{x}$ governs the speed of adjustment to steady-state levels of government debt to ensure solvency; in our benchmark results we use lump-sum transfers for this function $\left(\varphi_{T R}>0, \varphi_{x \neq T R}=0\right)$. To calculate fiscal multipliers we apply a two-year equally distributed shock to each fiscal instrument $(z=8)$. Within this framework we vary two parameters: the length of the ZLB (which we assume to be exogenous to the fiscal intervention); and the level of persistence of the shock after the eight-quarters are over $\left(\rho_{x}\right) 4^{4}$

These experiments, therefore, incorporate a short term temporary component followed by a persistent element once this initial response has been exhausted. Note that when $\rho_{x}=0$, the fiscal intervention is strictly temporary, and when $\rho_{x}=1$ it is permanent. Further note that $\rho_{x}$ represents agents' expectations of future fiscal actions, before these are realised. In this respect we use this variable to represent the credibility of the fiscal intervention. For example, when the government states that a fiscal movement is permanent, if agents do not believe this (independent of future actual intentions) in our analysis this would be

\footnotetext{
${ }^{4}$ Note that similar results would prevail more broadly with 'monetary accommodation', but we focus on the ZLB given its empirical relevance.
} 
represented by $\rho_{x}<15^{5}$

\subsection{Aggregation and market clearing}

Equilibrium in the goods market ensures that the supply of final goods (given by (50) is equal to public and private consumption and investment subject to a resource cost given by the dispersion in prices as a result of the Calvo pricing structure; equilibrium in the labour market requires the supply of labour be equal to that demanded by both the private and public labour market, again subject to resource costs from wage dispersion. Aggregation across households in consumption, labour, bonds, capital investment and profits distributed from intermediate goods producers is provided through an aggregation of quantities from each type of households weighted by the proportion in the population $\sqrt[6]{6}$ A complete list of all model equations, including optimisation conditions can be found in the Appendix..$^{7}$

\section{Fiscal outcomes}

\subsection{Fiscal multipliers}

In order to jointly examine the possibility of both expansionary contractions and fiscal free lunches, we propose employing a new metric of 'bond' multipliers, in addition to (traditional) output multipliers. Consider the following expression:

\footnotetext{
5 Lemoine \& Lindé $(2016)$ adopt an alternative approach in assessing credibility in their analysis of implications of credibility for fiscal policy effectiveness. In their set-up, full-credibility represents the case where agents know the present and the future path of permanent shocks. In contrast, in the no-credibility case, agents believe that all shocks are temporary irrespective of the observed consumption path. In the intermediate case of imperfect credibility, agents learn about the spending shocks through Kalman filtering as shocks are not directly observed.

${ }^{6}$ Note that in the case of bonds, capital, investment and profits this weighted average will only include those from Ricardian households as non-Ricardian agents are assumed not to engage in these markets. The aggregate level of any household quantity variable $\left(Z_{t}(i)\right)$ expressed in per-capita terms is given by: $Z_{t}=\int_{0}^{1} Z_{t}(i)=(1-\lambda) Z_{t}^{R}+\lambda Z_{t}^{N R}$.

${ }^{7}$ The model is solved using a second-order approximation with perturbation methods in Dynare.
} 


$$
m_{k}^{n}=\frac{\sum_{j=0}^{n}\left(k_{t+n}-k_{0}\right)}{\sum_{j=0}^{n}\left(x_{t+n}-x_{0}\right)}
$$

where $m$ denotes the relevant multiplier, $k$ is the relevant outcome/variable, $n$ is the time horizon over which the multiplier is measured, and $x$ is the respective fiscal instrument. When $k=Y$ equation (10) reduces to traditional output multipliers; a negative (positive) output multiplier when fiscal action is based on spending (taxes) represents spending cuts (tax increases) raising output, and hence expansionary contractions 8 However, these traditional output multipliers only provide partial information on the outcome of fiscal intervention because where the government may be stimulating with one instrument they may be contracting with another, dampening values of (10). Further, these multipliers do not reflect the 'value-for-money' of the fiscal intervention, something which has received heightened importance during the recent global recession.

When $k=B$ equation (10) produces 'bond multipliers', our suggested metric for calculating the budgetary consequences of each fiscal action. As such, a negative (positive) bond multiplier when fiscal action is based on spending (taxes) implies higher spending (lower taxes) reducing public debt, hence fiscal free lunches. The use of bond multipliers is particularly important at the ZLB because the path of government debt can be very different at the ZLB from that in normal times. Moreover, during severe recessions, the budgetary implications of each fiscal action gain increased significance both on efficiency grounds and for political feasibility. Hence, for a true valuation of the cost of a fiscal action at the ZLB it is crucial to incorporate the resulting changes in government borrowing following each policy experiment.

\footnotetext{
${ }^{8}$ For government spending instruments $\left(G^{C}, I^{G}, N^{G}, T R\right)$ we set each shock such that the change is equal to $1 \%$ of steady-state output. To ensure comparability of multipliers across fiscal instruments, we shock taxes rates such that the change in steady-state tax revenue is also equal to $1 \%$ of steady-state output. For example, in the case of government investment and consumption taxes, respectively, the shock is 0.5 $(0.5 \times I G / G D P=0.01)$ and $0.0804\left(0.0804 \times \tau^{c} \times C / G D P=0.01\right)$; see Section 3.2 for details of calibrations. In this way we ensure that there is comparability across fiscal experiments such that there is either $1 \%$ of GDP increase in spending or $1 \%$ of GDP decrease in revenues.
} 


\subsection{Calibration}

We set the discount factor $(\beta)$ to 0.99 , implying a steady-state annual real interest rate of 4 per cent. The depreciation rate in the private sector $(\delta)$ is calibrated to be 0.025 implying an annual depreciation of capital equal to 10 per cent. The inverse Frish elasticity is set to 1 ; habit persistence to 0.6 ; the share of capital in production to 0.35 ; the elasticity of substitution in the intermediate goods and labour market are set to 7.67 ; price and wage stickiness to 0.85 ; and the price and wage indexation parameters to 0.9 ; all standard values in the literature (see for example Smets \& Wouters 2003, Christiano et al. 2005, Coenen et al. 2013, Erceg \& Lindé 2014). This calibration implies that the slope of the new Keynesian Phillips curve is 0.015 , which is in line with estimates in the literature (see for example Smets \& Wouters 2003). The share of credit constrained households is set to 0.3 and the investment adjustment cost to 8 . The Taylor rule parameters are set such that, $\rho=0.85$, $\rho_{\pi}=1.5$ and $\rho_{y}=0.25$.

Steady-state tax rates on consumption, labour and capital income, and employer social security contributions $\tau^{c}, \tau^{l}, \tau^{k}$ and $\tau^{e r}$ are set at $0.2,0.23,0.29$, and 0.07 respectively and the level of steady-state government debt is set at 60 per cent of annual output. We select a slightly lower value of the depreciation of public capital compared to private capital with $\delta_{g}=0.02$, and we fix the share of public employment in total employment at 0.15 . The elasticity of public capital in the production function, $\alpha_{g}$, is set at 0.02 which is within the range of estimates in the literature (see Stähler \& Thomas 2012). We fix the share of public investment in GDP at 0.02 and the share of public consumption at 0.2. The above calibration implies the ratio of private investment and consumption to GDP is 0.16 and 0.62 respectively. We set our debt aversion parameter, $\varphi_{T R}$, to 0.18 such that debt is repaid slowly over the long run (it takes over 100 quarters for debt to halve); as we focus on short and medium run multipliers our results are not impacted significantly by this parameter (sensitivity on this is performed in Section 3.4 below). This calibration of fiscal parameters is in line with those values in the United Kingdom, and not too dissimilar from those for 
other countries (see for example Bhattarai \& Trzeciakiewicz 2017).

\subsection{Results}

Figure1 1illustrates one-year cumulative output multipliers for all eight fiscal instruments, one for each panel. ${ }^{9}$ Each coordinate plots a different multiplier value for the given length of ZLB ( $x$-axis) and the scale of fiscal persistence ( $\rho_{x}: y$-axis). These coordinates create contours and the solid line in the plots represents the contour for multipliers of value zero: this divides the plots into regions of conventional Keynesian effects (positive multipliers for spending instruments and negative for tax instruments) and potential expansionary contractions. As stated above, in the case of government spending (a term we use to incorporate all spending on public consumption, investment and employment) negative multipliers above the zero line represent the case of expansionary contractions as opposed to conventional positive Keynesian multipliers underneath this line, as displayed in the first three panels of Figure 1. In the case of taxes, the zero line separates the conventional negative multipliers region and the positive multipliers region associated with expansionary contractions.

The effectiveness of fiscal policy at the ZLB is determined by its role in influencing inflation. As discussed in Erceg \& Lindé (2014), when nominal interest rates are fixed, an increase in inflation following a fiscal expansion leads to a fall in the real interest rate which subsequently increases private consumption and investment, amplifying the impact of policy. As such, the results from the eight fiscal instruments presented in Figure 1 are separated into two groups depending on the impact each instrument has on inflation. In the case of government consumption, investment and employment, transfers and consumption taxes, expansionary policy results in inflationary pressure which leads to an amplification of output multipliers when the horizon of the ZLB increases; higher inflation leads to a more

\footnotetext{
${ }^{9}$ Note that under conditions of typical persistence levels and no monetary accommodation, impact (onequarter) multipliers are larger than four-quarter cumulative multipliers; we present the latter in order to consider a longer horizon for the fiscal action; however, both of these estimates are in line with much of the (diverging) empirical literature on multipliers. Sensitivity of our main results to the time horizon used is examined in Section 3.4 below.
} 


\section{Figure 1: One-year cumulative output multipliers}
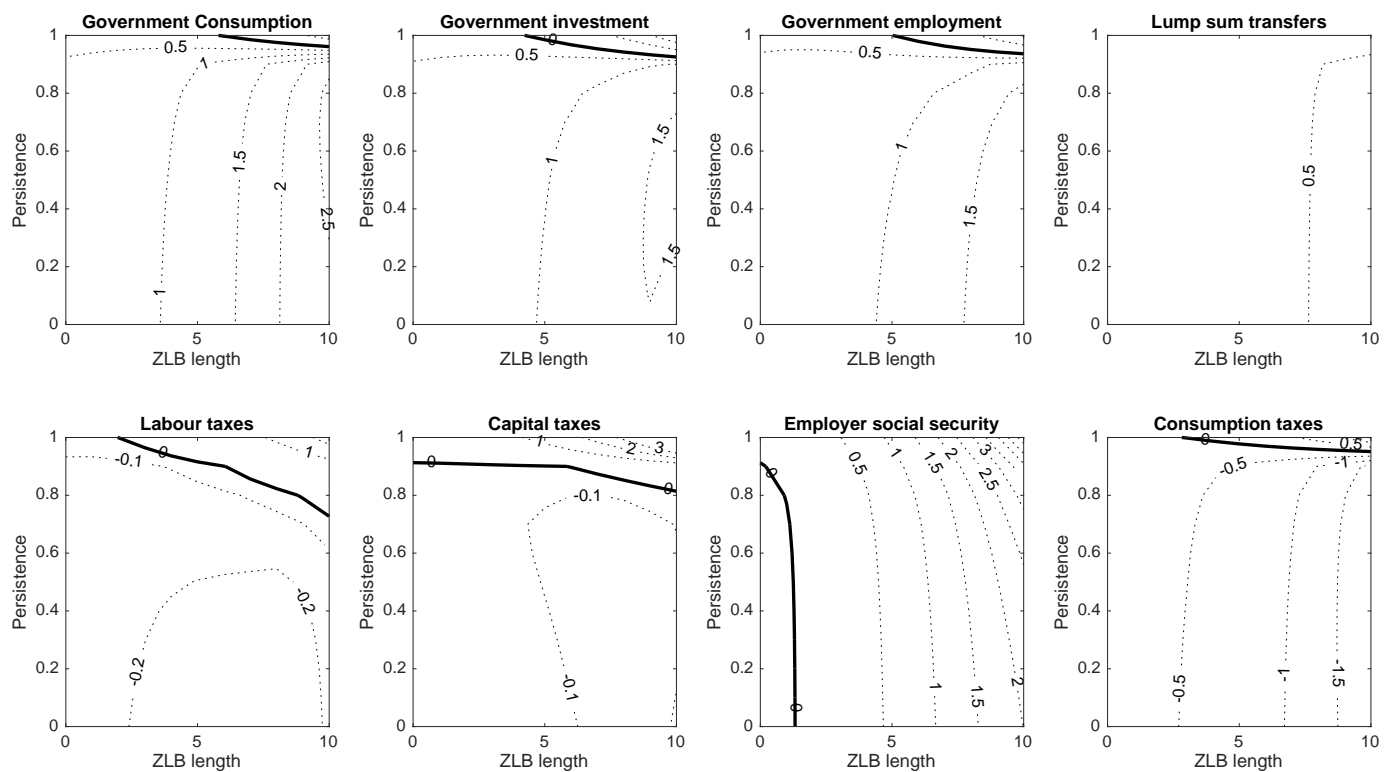

One-year cumulative output multipliers for the eight fiscal instruments at different levels of persistence and ZLB. The solid black line represents the contour where multipliers are equal to zero, separating between regions of traditional Keynesian outcomes and expansionary contractions.

negative real interest rates which subsequently crowds in further private demand. At low levels of persistence $\left(\rho_{x}<0.9\right)$ this amplification leads to higher output multipliers for these instruments. Note that a rise in government investment also raises the productive capacity of the economy putting a break on the extent to which prices rise. As a result, the drop in real interest rates is smaller leading to government investment multipliers being smaller than those of government consumption.

In the case of labour and capital taxes and employer social security contributions the reverse is true; cuts in these lead to deflationary pressure as costs to firms reduce. As such, expansionary contractions are represented by the area to the right of the solid line in the panels where government spending (consumption, investment and employment) multipliers are negative and tax multipliers are positive (tax rises leading to higher output). Rises in labour and capital taxes and employer social security contributions lead to inflation in the economy which at a period of fixed nominal interest rates leads to a crowding in of private 
demand such that output increases. This effect is strongest for employer social security contributions, where potential expansionary contractions are possible at all horizons beyond one period of ZLB. This occurs because whereas capital and labour taxes are transmitted through investment and labour market interactions, employer social security contributions are paid by firms and thus directly and immediately impact marginal costs and subsequently inflation; a result also identified in Eggertsson (2010) for production based taxes. Our fiscal multipliers, as presented in Figure1, are closely aligned with those reported by Coenen et al. (2012) who utilize seven separate structural DSGE models in assessing the effectiveness of fiscal stimulus 10

As fiscal persistence increases in these experiments (up to some critical value), in the case of the first group of instruments where expansionary policy leads to inflationary pressure, the amplification of multipliers which occurs at higher levels of ZLB is reduced as more of the fiscal activity is occurring after the period of the ZLB, when normal circumstances are resumed. Fully rational agents build this into their expectations, and subsequently a reduced impact of inflation occurs, alleviating the amplification of results the ZLB creates. When fiscal persistence is high, the impact of government spending on public consumption, investment and employment and of consumption taxes is reversed; austere fiscal actions lead to increases in output (expansionary contractions) and this is increased at longer periods of the ZLB. Fully rational agents who expect austerity to persist for a long time observe an increase in their expected lifetime income from a smaller future government, and hence in their consumption. This, in turn, leads to an increase in demand and inflation and when the nominal interest rate does not respond, a fall in the real interest rate; this leads to further consumption and further inflation. These periods of expansionary contractions are observed in the top right corner of the first three panels in the top row and the last panel of the

\footnotetext{
10 Coenen et al. (2012) present results from experiments with the ZLB and fiscal shock lasting two years and find average first year multipliers of 1.20 for government consumption, 1.59 for government investment, 0.42 for general transfers, 0.61 for consumption taxes and 0.23 labour income taxes for the US economy (average over seven different DSGE models, with similar results for the Europe). Our results (see Figure 1) are within the range of results reported in Coenen et al. (2012).
} 
bottom row of Figure 1 which demonstrates that these episodes are possible when agents expect that the cut in spending will persist for a long time. Lemoine \& Lindé $(\sqrt{2016})$ also find that limited credibility has an adverse impact on the effectiveness of fiscal consolidation and this effect is particularly pronounced in the case of a small country operating as a member of a currency union and hence without independent monetary policy.

Figure 2 illustrates one-year cumulative bond multipliers for all eight fiscal instruments, where the presentation is in line with that for Figure 1; here the black line in each plot represents the contour for bond multipliers of value zero, which identifies the regions of potential fiscal free lunches. Figure 2 demonstrates that fiscal free lunches are possible for government consumption and government employment in the bottom right hand corner of these plots, where bond multipliers go from positive (more spending leading to more debt) to negative (more spending reducing debt); and from negative for consumption taxes (raising taxes reducing debt) to positive (raising taxes raising debt). This supplements the results from Figure 1 where it was found that when the fiscal action is constrained to the period of the ZLB, and when the fiscal action is inflationary if expansionary, large output multipliers can be achieved. These output multipliers can be so large that the tax base is increased sufficiently to more than pay for the initial fiscal intervention. Fiscal free lunches are not possible with cuts in labour and capital taxes or government investment due to the supplyside effects discussed above.

\subsection{Sensitivity}

To consider when each extreme fiscal outcome is most likely, Figure 3 combines and summarises Figures 1 and 2 illustrating both the regions of expansionary contractions and fiscal free lunches under a number of different scenarios. For brevity, only results for government consumption are presented, results also hold for other fiscal instruments (not reported). The first panel in Figure 3 presents the benchmark results from above; the other panels explore a number of different model features and calibrations. 
Figure 2: One-year cumulative bond multipliers
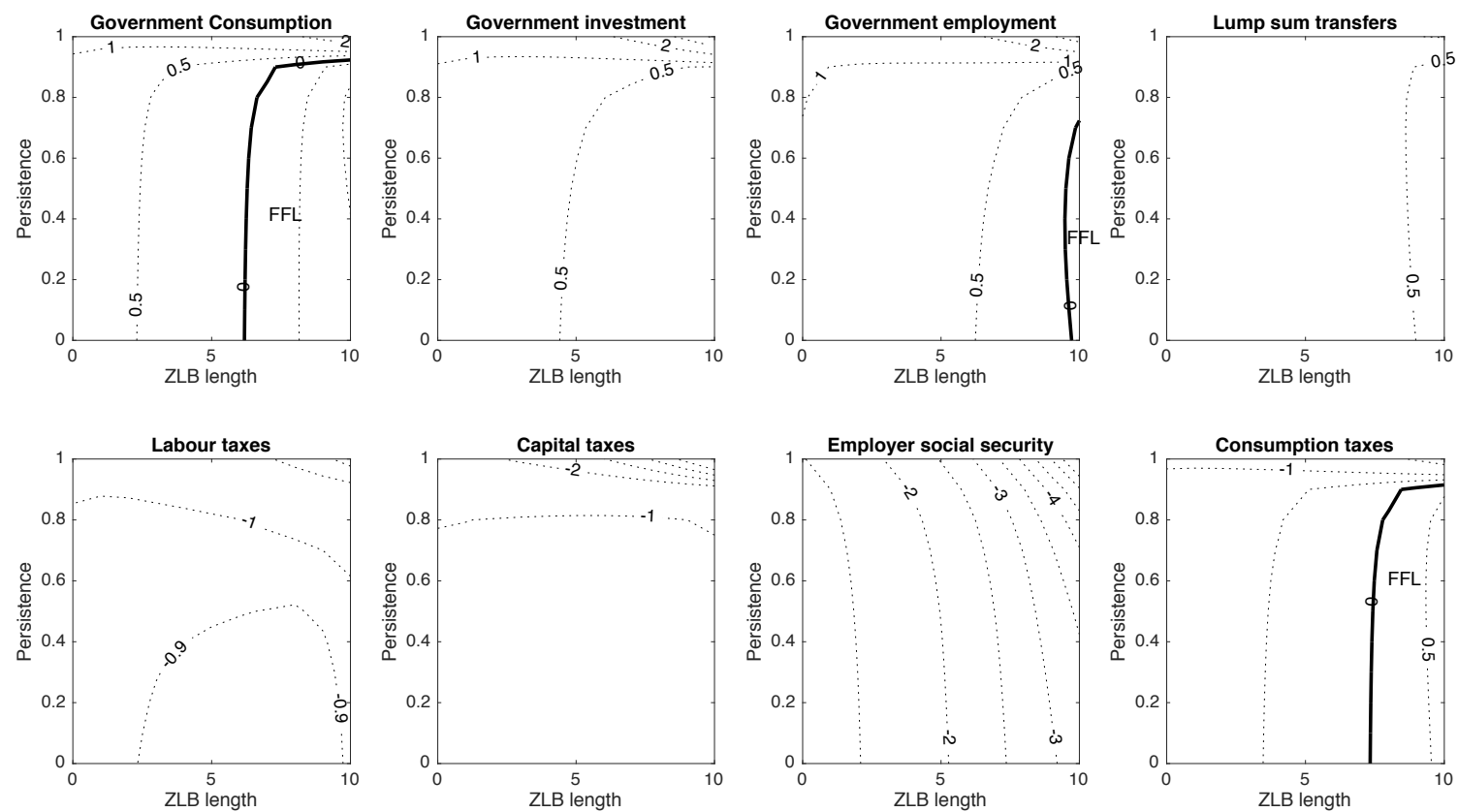

One-year cumulative bond multipliers for the eight fiscal instruments at different levels of persistence and ZLB. The solid black line represents the contour where multipliers are equal to zero, separating between regions of fiscal free lunches (areas annotated 'FFL') and conventional outcomes. 


\section{Figure 3: Further extensions}
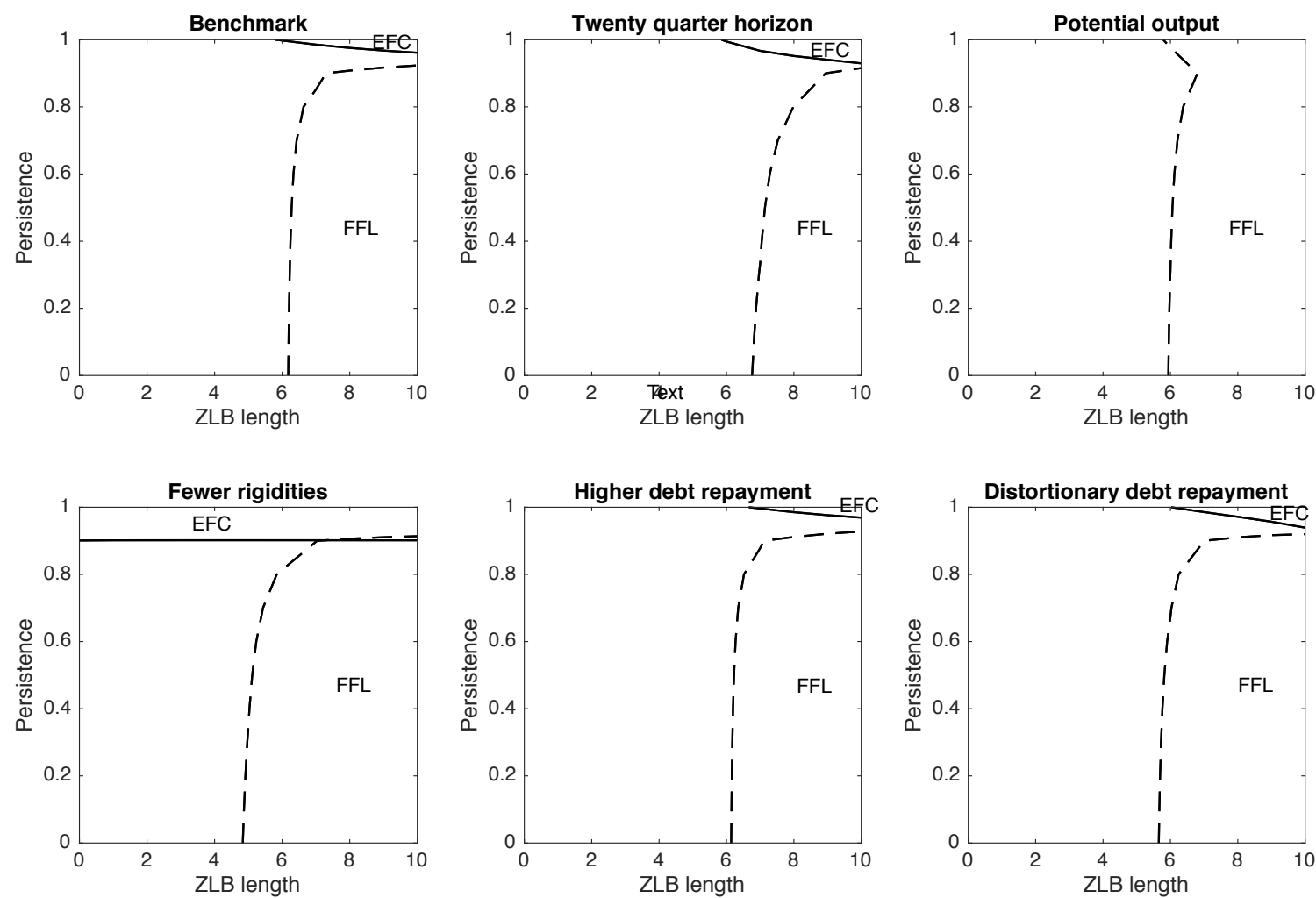

Plots detailing output and bond contours with government consumption multipliers of zero value (the solid and dashed lines, respectively) under different scenarios as described by the panel headings. When output multipliers are negative, expansionary fiscal contractions are possible (areas annotated 'EFC') and similarly negative bond multipliers represent potential fiscal free lunches (areas annotated 'FFL'). The first panel represents the benchmark from above; the second, when cumulative output multipliers are measured over 20 quarters $(n=20$ in $10 p)$; the third when the model consistent output gap (deviations of actual output from potential output) rather than the trend output gap (deviations of output from steady-state) enters the Taylor rule (6); the fourth where all rigidities in the model are removed with the exception of sticky prices and where all households are Ricardian $(\lambda=0)$; the fifth with different calibrations of the debt repayment parameter $\left(\varphi_{T R}\right)$; and the sixth when distortionary consumption taxes are used to respond to movements in debt $\left(\varphi_{\tau^{c}<0}\right)$. 
The second panel of Figure 3 demonstrates that expansionary fiscal contractions and fiscal free lunches are also present when measured over a longer horizon; with cumulative multipliers calculated over twenty quarters, the region associated with the former extreme fiscal outcome is larger and the latter smaller, although the differences from the benchmark are minimal. As highlighted by Erceg \& Lindé (2014), these multipliers represent marginal not average values, whereby the two diverge if policy is able to alter the length of the ZLB.

The third panel of Figure 3 presents an economy where the Taylor rule (6) responds to the model consistent output gap (defined as deviations of actual GDP away from an economy with no nominal rigidities) and not the trend output gap (deviations of actual output from steady-state) as in the benchmark case. Fiscal free lunches are still possible at similar levels of ZLB as before; however, expansionary contractions no longer occur with this specification of the Taylor rule. Although the Taylor rule is not operational during the period of the ZLB (as nominal rates are fixed at zero) the future path of interest rates are important for forward looking agents. In the case of a permanent cut in government spending, the model consistent output gap is smaller than the trend output gap, and as such, the path of nominal interest rates are higher. Therefore, whereas in our benchmark scenario Ricardian agents see an increase in lifetime earnings in the presence of a persistent cut in government spending, this is muted when interest rates are less sensitive to the fiscal action, and as such, expansionary contractions are no longer possible for spending instruments as sufficient crowding in does not occur 11 That is, our model predicts that for expansionary fiscal contractions to be possible monetary stimulus is also required.

The fourth panel of Figure 3 presents results where all rigidities in the model are removed with the exception of price stickiness and where all households are Ricardian $(\lambda=0)$; this is in line with much of the ZLB literature which tends to adopt smaller models for analysis (see for example Eggertsson 2010, Erceg \& Lindé 2014). As stressed above, it is

\footnotetext{
${ }^{11}$ In general, output multipliers are lower and less extreme when interest rates respond to the model consistent output gap as paths of future nominal interest rates are also less extreme; that is, the model consistent output gap fluctuates less than the trend output gap in response to fiscal stimuli which dampens fiscal multipliers.
} 
the fiscal instrument's interaction with inflation which is the key to the impact of the ZLB on multipliers, and when rigidities are removed this interaction is more immediate hence extreme fiscal actions become more plausible. In the smaller version of the model both fiscal free lunches and expansionary contractions become possible at longer lengths of the ZLB and higher levels of fiscal persistence.

We also test the robustness of results to the speed and method of debt repayment. Maintaining the use of lump-sum transfers to repay debt and increasing the speed with which this is performed (increasing $\varphi_{T R}$ ) has a limited quantitative impact on the results (the fifth panel in Figure 3) ${ }^{12}$ Further, changing the instrument which repays additional debt or surpluses arising from the fiscal action also has limited impact on the quantitative results above. For example, in the sixth panel of Figure 3 we allow consumption taxes to respond to movements in debt such that steady-state debt is reached in the long run, and the results are in line with the benchmark 13

Drautzburg \& Uhlig (2015) illustrate that multipliers, especially in the long run, are substantially impacted by both the instrument which repays debt and the speed with which this is performed ( $\varphi_{x}$ in our model); for example, Drautzburg \& Uhlig (2015) find that using labour taxes (rather than lump-sum taxes) to repay debt that arise as a result of higher government consumption can reduce one year multipliers by nearly $20 \%$ and can make long run multipliers go from positive to negative and these effects are amplified by increasing the speed of debt repayment. With our model, we have in principle 64 separate fiscal experiments that can be performed by varying the instrument which is first shocked and the instrument which then subsequently moves government debt to its steady-state; further, within these individual experiments the speed of debt repayment $\left(\varphi_{x}\right)$ can be varied. Our core results are qualitatively unchanged with fiscal response functions as in (9) where one instrument is

\footnotetext{
${ }^{12}$ The calibration of $\varphi_{T R}$ in the benchmark is 0.18 versus 0.5 in the fifth panel of Figure 3 this leads to half of peak debt being repaid within nine years in this extension compared with a negligible (slow) repayment of debt in our benchmark calibration.

${ }^{13}$ We have performed tests of robustness on using different instruments beyond lump-sum transfers and consumption taxes and the results remain similar to those presented above.
} 
stimulated and then another responds to lag movements in debt away from steady-state at reasonable calibrations of $\varphi_{x}$. That is, the impact of the ZLB dominates our results to the extent that if the repayment of debt is performed predominately after the ZLB period, even rapidly so, the results are in line with those presented above. With very large calibrations of $\varphi_{x}$ larger deviations from our benchmark results can be obtained especially for long run multipliers (as demonstrated by Drautzburg \& Uhlig 2015), as there is more than one fiscal instrument responding strongly during the period of monetary accommodation.

\subsection{Discussion}

As is seen above, our model has incorporated the possibility of both expansionary fiscal contractions and fiscal free lunches. The former occur under two sets of circumstances: when fiscal action is inflationary; and, when agents expect austerity to persist such that their lifetime income is increased. We have also found that fiscal free lunches are possible with policies that increase demand during a period of the ZLB. Further, for fiscal free lunches to occur policies must respond quickly to the ZLB, and should not persist beyond the length of the monetary accommodation. We conclude therefore that both extreme fiscal outcomes are unlikely, especially during economic downturns (when the ZLB is most likely).

Regarding austerity, the experience of the recent global financial crisis has indicated that austere policies come at a political cost which, when combined with electoral cycles, makes it unlikely for agents to believe that such policies will continue for extended periods 14 If austerity is to be expansionary it needs to be credibly persistent. Existing empirical evidence suggests that more persistent consolidation episodes are those cutting more politically sensitive spending, whereas cuts in public investment are more associated with short lived budget adjustments (von Hagen et al. 2002); when a government takes a more unpopular

\footnotetext{
${ }^{14}$ Since 2012, the electorate punished pro-austerity parties decisively in countries as diverse as Canada, France, Greece, Iceland, Scotland and Spain. Although this is not a uniform rule (for example Germany and the UK have not seen similar political swings) many of these examples relate to political parties specifically opposing austerity measures. The presence and the strength of the anti-austerity opposition would have provided some doubt over the persistence of such fiscal measures.
} 
decision (cutting specific wages and transfers versus abstract investment projects) more political credibility is obtained. Similarly, it is also shown that consolidations which are against type for a given political party (spending cuts on the political-left and tax increases on the political-right) are more likely to persist, the argument being that going against expectations buys credibility and that these actions are less likely to be reversed by a change in government (Tavares 2004).

Interestingly, fiscal consolidations are more likely to be adopted with a strong domestic economy in the years up to the start of the adjustment; however, those consolidations adopted during periods of lower economic growth are more likely to be long lasting (von Hagen \& Strauch 2001). This poses a clear paradox, fiscal adjustments performed during periods of weak economic conditions improve credibility such that the action is more likely to be long lasting, but are also less likely to occur given the political cost of such decisions. Hence, the credibility of fiscal austerity is key to its impact on output, as is established by our formal results.

Overall, we suggest that expansionary fiscal contractions are unlikely, an argument supported by the rare examples of these events in practice. For example, even if the question of causality is ignored, Alesina \& Ardagna (2010) finds successful expansionary contractions to be the exception rather than the rule (occurring in nine separate instances in 21 OECD countries between 1970 and 2007). The great majority of other existing work find fiscal consolidations to be contractionary (see for example Callegari et al. 2012, Bi et al. 2013, Guajardo et al. 2014, among others).

Similarly, regarding stimulus, it is well-known that fiscal authorities are slow to respond to economic circumstances and are less likely to stop expansionary policies after normal circumstances are restored (Blinder 2004). Hence, timely and short-lived expansions which are prerequisites for fiscal free lunches, are not common places. Indeed, lags in fiscal policy action are widely observed, arising from both administrative and political reasons, especially in countries with weak political party discipline, such as the US. The American Recovery 
and Reinvestment Act of 2009 that was put in place in response to the sharpest downturn in economic activity since the Great Depression of the 1930s soon after President Obama took office can be seen as an exception. Even then it took a year for the majority of the changes to transfers and expenditures to take place (Auerbach 2012). Fiscal free lunches are possible in our model with monetary accommodation not constrained by the lower bound, but such accommodation in a period of central bank independence with a strong focus on inflation targeting is also unlikely.

Our model suggests that, under the conditions of monetary accomodation or the ZLB, fiscal free lunches are more feasible than expansionary contractions. Indeed, areas in Figure 3 relating to fiscal free lunches under all the different extensions are larger than those relating to expansionary contractions. As yet, however, whereas the literature on potential expansionary contractions is large, there are no studies (to our knowledge) which test for fiscal free lunches.

\section{Conclusions}

This paper has demonstrated that extreme fiscal outcomes are possible, but unlikely given political constraints. Persistent austerity (needed for expansionary contractions) is rare, especially during downturns when the electorate is in economic distress. Responsive and temporary expansions (required for a fiscal free lunch) are unlikely, we argue, with policymakers unwilling to reverse expansions. Recent evidence across a wide range of episodes reveals that fiscal austerity has indeed been contractionary. Regarding fiscal stimulus, there is as yet no systematic empirical evidence to support the existence of fiscal free lunches. Our work points to the importance of budgetary outcomes arising from fiscal action as an important avenue for future research. 


\section{References}

Alesina, A. \& Ardagna, S. (1998), 'Tales of fiscal adjustments', Economic Policy 27(24), 489545.

Alesina, A. \& Ardagna, S. (2010), 'Large changes in fiscal policy: taxes versus spending', Tax Policy and the Economy 24(1), 35-68.

Auerbach, A. \& Gorodnichenko, Y. (2012), 'Measuring the output responses to fiscal policy', American Economic Journal: Economic Policy 4(2), 1-27.

Auerbach, A. J. (2012), 'The fall and rise of Keynesian fiscal policy', Asian Economic Policy Review $7(2), 157-175$.

Bhattarai, K. \& Trzeciakiewicz, D. (2017), 'Macroeconomic impacts of fiscal policy shocks in the UK: A DSGE analysis', Economic Modelling 61, 321-338.

Bi, H., Leeper, E. M. \& Leith, C. (2013), 'Uncertain fiscal consolidations', The Economic Journal 123(566), F31-F63.

Blinder, A. S. (2004), The case against the case against discretionary fiscal policy, Center for Economic Policy Studies, Princeton University.

Callegari, G., Melina, G. \& Batini, N. (2012), Successful austerity in the United States, Europe and Japan, Technical report, International Monetary Fund.

Calvo, G. (1983), 'Staggered prices in a utility-maximizing framework', Journal of Monetary Economics 12(3), 383-398.

Christiano, L., Eichenbaum, M. \& Evans, C. (2005), 'Nominal rigidities and the dynamic effects of a shock to monetary policy', Journal of Political Economy 113(1), 1-45.

Christiano, L., Eichenbaum, M. \& Rebelo, S. (2011), 'When is the government spending multiplier large?', The Journal of Political Economy 119(1), 78-121. 
Coenen, G., Erceg, C., Freedman, C., Furceri, D., Kumhof, M., Lalonde, R., Laxton, D., Lindé, J., Mourougane, A., Muir, D. et al. (2012), 'Effects of fiscal stimulus in structural models', American Economic Journal: Macroeconomics 4(1), 22-68.

Coenen, G., Straub, R. \& Trabandt, M. (2013), 'Gauging the effects of fiscal stimulus packages in the Euro area', Journal of Economic Dynamics and Control 37(2), 367-386.

Drautzburg, T. \& Uhlig, H. (2015), 'Fiscal stimulus and distortionary taxation', Review of Economic Dynamics 18(4), 894-920.

Eggertsson, G. (2010), 'What fiscal policy is effective at zero interest rates?', NBER Macroeconomics Annual 2010 25, 59-112.

Erceg, C. \& Lindé, J. (2014), 'Is there a fiscal free lunch in a liquidity trap?', Journal of the European Economic Association 12(1), 73-107.

Guajardo, J., Leigh, D. \& Pescatori, A. (2014), 'Expansionary austerity? International evidence', Journal of the European Economic Association 12(4), 949-968.

Lemoine, M. \& Lindé, J. (2016), 'Fiscal consolidation under imperfect credibility', European Economic Review 88, 108-141.

Smets, F. \& Wouters, R. (2003), 'An estimated dynamic stochastic general equilibrium model of the Euro area', Journal of the European Economic Association 1(5), 1123-1175.

Stähler, N. \& Thomas, C. (2012), 'FiMod - a DSGE model for fiscal policy simulations', Economic Modelling 29(2), 239-261.

Tavares, J. (2004), 'Does right or left matter? Cabinets, credibility and fiscal adjustments', Journal of Public Economics 88(12), 2447-2468.

von Hagen, J., Hallett, A. \& Strauch, R. (2002), 'Budgetary consolidation in Europe: Quality, economic conditions, and persistence', Journal of the Japanese and International Economies 16(4), 512-535. 
von Hagen, J. \& Strauch, R. (2001), 'Fiscal consolidations: Quality, economic conditions, and success', Public Choice 109(3-4), 327-346.

Woodford, M. (2011), 'Simple analytics of the government expenditure multiplier', American Economic Journal: Macroeconomics 3(1), 1-35. 


\section{A Model equations}

\section{Table A1: Model equations}

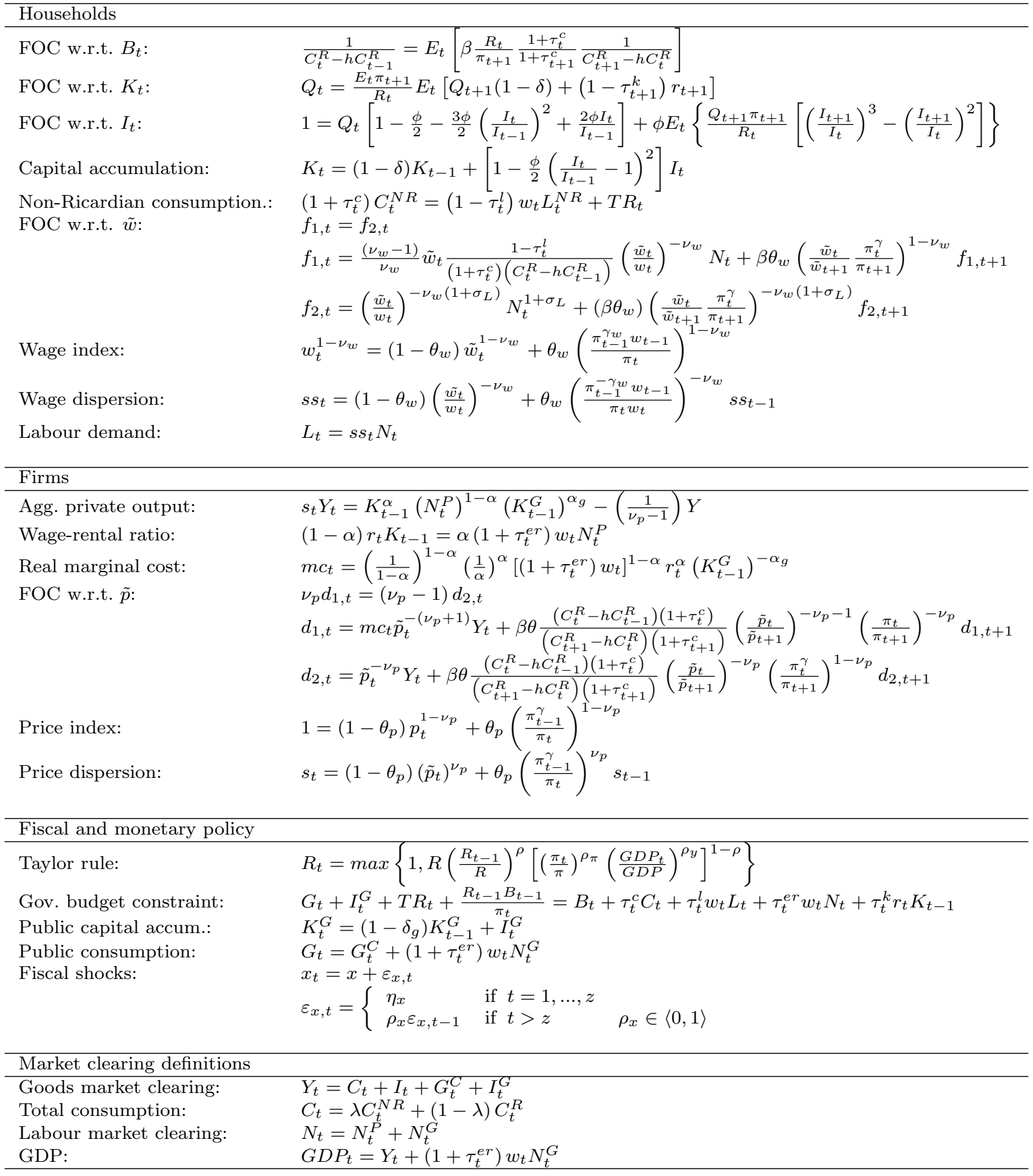

Note: All quantities are in per capita terms. $Q_{t}$ is the shadow price of capital; $d_{1}$ and $d_{2}$ are expressions that allow us to present the first-order condition for $\tilde{p}_{t}$ (the price which maximises profits for intermediate firm producers at time $t$ ) in a recursive form; $f_{1}$ and $f_{2}$ are expressions that allow us to present the first-order condition for $\tilde{w}_{t}$ (the wage which maximises profits for trade unions at time $t$ ) in a recursive form; $s_{t}$ is a measure of price dispersion; and $s s_{t}$ a measure of wage dispersion. All other variables are as defined in the main body of the paper. 